
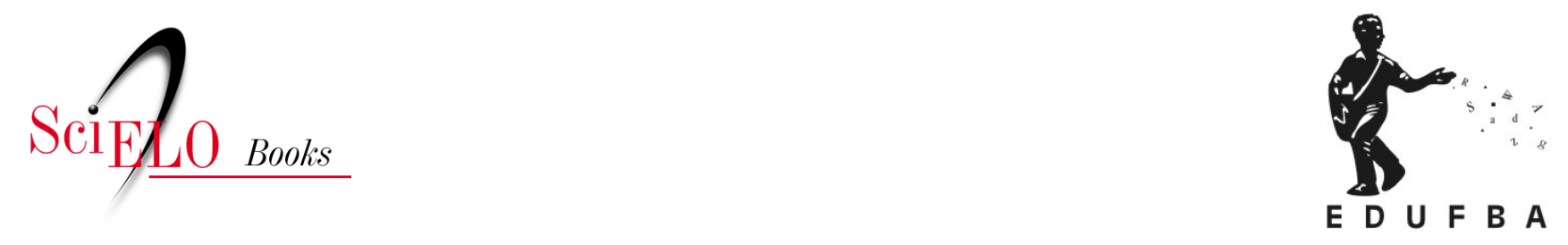

\title{
Uso de neblina ativada para redução das emissões de bioaerossóis em um aterro sanitário
}

\author{
Tania Mascarenhas Tavares \\ Eagles M. Alves \\ Carolina L. Wilches Arciniegas
}

\section{SciELO Books / SciELO Livros / SciELO Libros}

TAVARES, T.M., ALVES, E.M., and ARCINIEGAS, C.L.W. Uso de neblina ativada para redução das emissões de bioaerossóis em um aterro sanitário. In: FERNANDES, R.C.P., LIMA, M.A.G., and ARAÚJO, T.M., comps. Tópicos em saúde, ambiente e trabalho: um olhar ampliado [online]. Salvador: EDUFBA, 2014, pp. 313-331. ISBN: 978-65-5630-012-2. https://doi.org/10.7476/9786556300122.0016. \section{International license.}

All the contents of this work, except where otherwise noted, is licensed under a Creative Commons Attribution 4.0

Todo o conteúdo deste trabalho, exceto quando houver ressalva, é publicado sob a licença Creative Commons Atribição 4.0. 


\section{Uso de neblina ativada para redução das emissões de bioaerossóis em um aterro sanitário}

Tania Mascarenhas Tavares

Eagles M. Alves

Carolina L. Wilches Arciniegas

\section{Introdução}

Aterros sanitários emitem bioaerossóis continuamente para o meio ambiente, principalmente bactérias e fungos, que podem ser transportados a longas distâncias, representando um risco potencial não apenas para os trabalhadores do empreendimento, mas também para os residentes nas áreas do seu entorno. Descreve-se aqui o desenvolvimento de um novo sistema para a purificação do ar emitido da lagoa de chorume de um aterro sanitário, de baixo custo e eficiência, de purificação estável, que não gera resíduos sólidos e cujos efluentes líquidos atendem aos padrões de qualidade internacionais. O sistema é composto de um reator na saída dos gases da lagoa, onde os microorganismos são captados por um sistema de neblina ativada quimicamente e conduzidos para o esgotamento sanitário, liberando o ar purificado para a atmosfera. O sistema desenvolvido comprovou a viabilidade da redução de cerca de $93 \%$ das bactérias e fungos emitidos para a atmosfera pela lagoa de chorume do aterro sanitário metropolitano de Salvador.

Bactérias e fungos apresentam dimensões entre 0,01 $\mu \mathrm{m}$ e $100 \mu \mathrm{m}$ e têm o seu comportamento de transporte no ar governado pelos princípios da física, como qualquer outra partícula (MOHR, 2002), ou seja, pelos princípios da difusão, turbulência e gravitação. Baseado nesses princípios pode-se determinar a taxa de sedimentação de partículas no ar relacionado a suas dimensões e outras propriedades físicas. Estendendo 
esses conceitos aos microorganismos, é possível dizer que as bactérias apresentam uma taxa de sedimentação que varia entre 0,0015 - 0,0021 $\mathrm{m} \mathrm{min}^{-1}$, enquanto os esporos fúngicos, uma taxa de $0,029-2,89 \mathrm{~m}$ $\min ^{-1}$, se nos basearmos nas taxas de sedimentação das partículas no ar, segundo Frank (1937). A exposição aos fatores ambientais, como luz solar, temperatura, oxigênio e umidade do ar mais baixa - além da dessecação durante o transporte através do ar - provocam o decaimento natural dos microorganismos. (KOWALSKI; BAHNFLETH, 1998) Portanto, é de se esperar que os microorganismos não consigam ser transportados a longas distâncias de forma ativa.

Apesar de sua grande maioria ser rapidamente inativada, diversas bactérias e esporos fúngicos podem permanecer vivos e serem transportados pelo ar para regiões distantes do seu local de origem, especialmente os originados de atividades antrópicas, onde as concentrações podem vir a ser muito aumentadas. (RECER et al., 2001; ALBRECHT et al., 2008) Esse fato cria a necessidade de busca de mecanismos que reduzam os microorganismos emitidos para a atmosfera, mantendo assim o bem-estar e a saúde dos trabalhadores expostos, bem como dos moradores vizinhos à fonte. Embora muitos dos microorganismos emitidos em grande quantidade sejam comuns no ambiente, como pela decomposição de matéria orgânica, muitos podem causar infecções oportunistas, principalmente nas pessoas com saúde comprometida.

Somente a partir dos fins da década de oitenta do século passado, surgiram trabalhos mostrando que diversas plantas de produção animal e tratamento de resíduos, tanto urbano como industriais, envolvendo decomposição microbiana, levam ao aumento das emissões de microrganismos para o ar. Como resultado, bactérias e fungos que não existiriam em determinadas quantidades, passam a ser encontrados em altas concentrações, não apenas na atmosfera interna, mas também nas proximidades e até mesmos em pontos mais afastados dos focos de emissão. As principais fontes potencialmente emissoras de bioaerossóis do setor produtivo são: plantas de tratamento biológico de esgotamento sanitário e efluentes orgânicos industriais, estações de compostagem, plantas de classificação e separação de lixo, aterros sanitários, produção confinada de animais, plantas de beneficiamento de produtos animais e agrícolas, entre outros. 
Os estudos sobre emissões e transporte aéreo de bioaerossóis de plantas, de disposição e tratamento de resíduos líquidos e sólidos e os efeitos à saúde humana dessas atividades são limitados, focados principalmente em emissões de atividades de compostagem e foram desenvolvidos essencialmente na Alemanha. Por essa razão relatamos, a seguir, alguns desses estudos que comprovam a necessidade de desenvolvimento de técnicas de redução da emissão de bioaerossóis.

Em processos de compostagem, algumas das espécies de fungos, como Aspergillus e Penicillium são mais abundantes e são dispersos no ar em grande número. (CROOK; BARDOS; LACEY, 1988; FISCHER et al., 2000; FISCHER et al., 2008) Outro exemplo de fungo emitido por compostagem é o Aspergillus fumigatus, um bolor alergênico, tóxico e oportunista, isolado em todo o mundo e comum no meio ambiente por ser termotolerante. A sua concentração no ambiente natural é geralmente baixa quando comparada com outros fungos, como por exemplo o Cladosporium e Alternaria, que são dominantes e bem conhecidos em ambientes naturais. (FISCHER et al., 2000; MILLNER, 1995) A concentração de Aspergillus fumigatus pode aumentar no entorno das unidades de compostagem segundo Crook, Bardos e Lacey (1988), resultando na dominância deste, na direção a favor do vento em regiões próximas, sendo, portanto, uma indicação de emissões desse tipo de planta. (MILLNER, 1995; RECER et al., 2001)

Albrecht e seus colaboradores (2008) concluíram que as concentrações de microrganismos termotolerantes, emitidos por plantas de compostagem, têm que ser avaliadas em distâncias maiores que $300 \mathrm{~m}$ das instalações a jusante da direção dos ventos, para assegurar a ausência de contaminação proveniente da planta. Eles também comprovaram que as concentrações de fungos termotolerantes e actinomicetos termofílicos, a uma distância de 600-1400 m da planta, são uma a duas ordens de grandeza maiores em relação aos níveis naturais, verificando que durante a amostragem de bioaerossóis é essencial a avaliação das condições meteorológicas, como temperatura e umidade do ar, velocidade e direção do vento.

A comprovação que microorganismos na forma ativa são transportados a médias e longas distâncias pelo ar aponta para uma possível relação entre emissões de bioaerossóis, saúde e bem-estar, não apenas dos trabalhadores, mas também dos moradores vizinhos a aterros 
sanitários. Como já mencionado, muitos microrganismos, frequentes no meio ambiente não contaminado, podem causar infecções oportunistas nas pessoas com saúde comprometida, quando presentes em maiores concentrações. Além da suscetibilidade do indivíduo (grau de imunidade), a duração da exposição, a concentração do agente infeccioso, a dose infecciosa, a taxa de respiração e a rota da infecção (por inalação, olhos, nasofaringe, etc.), são fatores importantes para a aquisição de uma infecção transmitida pelo ar. (KOWALSKI; BAHNFLETH, 1998) Por exemplo, em uma pessoa saudável são necessários de 1 a 10 bacilos da tuberculose para provocar uma infecção, enquanto que um total de 200 Rhinovirus virions é necessário para causar um resfriado. Nenhum desses fatores é necessariamente um determinante absoluto, podendo a saúde ou o grau de imunidade serem tão importantes quanto a exposição prolongada ao ar. (KOWALSKI; BAHNFLETH, 1998)

Embora esses e outros trabalhos tenham mostrado que as altas concentrações de bioaerossóis não se restringem ao interior dessas plantas, mas também a pessoas vivendo no entorno de tais estações, o fato recebeu pouca atenção, tanto científica quanto política. Somente em meados deste século surgiram os primeiros estudos epidemiológicos relacionando causa-efeito da exposição ambiental a bioaerossóis provenientes de plantas de tratamento.

Herr e colaboradores (2004a) realizaram um estudo epidemiológico na Alemanha, do tipo transversal, com 356 indivíduos de uma área residencial próxima a uma estação de compostagem, com o objetivo de relacionar possíveis efeitos sobre a saúde com exposição a bioaerossóis. Medidas de bioaerossóis ao ar livre na área residencial (bactérias totais, fungos e actinomicetos termófila), mostraram concentrações maiores do que $10^{5} \mathrm{UFC} \mathrm{m}^{-3}$. Essas concentrações reduziam-se ao longo de 550 metros da estação de compostagem. Os dados foram analisados por regressão logística, indicando uma influência relevante da distância entre a casa e o local de uma planta de compostagem, com sintomas de irritação respiratória e queixas de saúde em geral, mas não resultando em maior prevalência de casos de alergias ou doenças infecciosas nos residentes expostos. Herr e colaboradores (2004a) concluíram que os efeitos observados sobre a saúde em associação com a exposição do bioaerossol ambiental, podem ser classificados como uma irritação das membranas da mucosa, recomendando que em próximas pesquisas 
sobre esse tema fosse necessário focalizar na função pulmonar e em anticorpos específicos contra fungos.

Em outro trabalho realizado por Herr e colaboradores (2004b), demonstraram uma associação entre poluição por bioaerossóis em áreas residenciais e queixas de irritação das vias aéreas, bem como uma excessiva fadiga e tremores, que são sintomas reportados em trabalhadores das estações de compostagem. Estas áreas residenciais, distando 200m das estações de compostagem, apresentaram níveis de actinomicetos termófilos, bactérias totais e fungos similares às exposições ocupacionais nessas estações.

Em 2006, Bunger e colaboradores compararam trabalhadores de estações de compostagem aos controles em 41 estações de compostagem alemãs (mistura de resíduos biodegradáveis domésticos acrescida de resíduos de estaleiros). As medidas revelaram concentrações elevadas de fungos e actinomicetos. Os trabalhadores apresentaram uma prevalência significativamente maior de irritação da mucosa dos olhos e das vias aéreas superiores, bem como maior frequência de conjuntivite e um declínio significativo na capacidade vital. Os resultados diferem dos trabalhadores expostos a poeiras orgânicas em outras instalações, talvez devido a fungos e bactérias termotolerantes em plantas. Bunger e colaboradores (2006) concluíram que a exposição à poeira orgânica em locais de trabalho de estações de compostagem está associada a efeitos respiratórios crônicos e agudos.

Igualmente na Alemanha, Müller e colaboradores (2006) verificaram que 17 jovens saudáveis que foram expostos a uma estação de compostagem por duas horas fazendo atividades moderadas, apresentaram alterações na contagem de células brancas do sangue, um aumento de neutrófilos e uma diminuição de eosinófilos. Os autores concluíram que as exposições de curto prazo de jovens saudáveis produzem leves alterações sistêmicas.

Esses estudos levaram o Conselho Ambiental Alemão a acreditar que os poucos trabalhos sobre a relação entre exposição a bioaerossóis e efeitos na saúde já são suficientes para justificar recomendações de medidas de proteção. Esse fato estimulou técnicos alemães a iniciar o desenvolvimento de sistemas de abatimento de bioaereossóis de plantas emissoras de microorganismos. 


\section{Sistemas de Abastecimento de Bioaerossóis}

Diferentes técnicas, baseadas em diferentes princípios, foram testadas em estação de compostagem, estações de tratamento de resíduos e estações de tratamento biológico, com o objetivo de reduzir exposição ocupacional a bioaerossóis e de suas emissões para a atmosfera através de uma combinação de engenharia de sistemas de controles. A seguir, descreveremos os sistemas desenvolvidos por outros grupos em outros países, assim como um novo sistema desenvolvido na Universidade Federal da Bahia-UFBA, para reduzir as emissões de bactérias e fungos da bacia de chorume de um aterro sanitário em Salvador, Bahia, resultado da parceria do Mestrado de Saúde, Ambiente e Trabalho com o Laboratório de Química Analítica Ambiental do Instituto de Química da UFBA e o extinto Centro de Pesquisas Ambientais da Universidade de Frankfurt (ZUF), tendo apoio financeiro da FAPESB, do CNPQ e da CAPES, este último sob a forma de bolsa de mestrado.

\section{Método}

Trata-se de uma descrição do sistema de abatimento de bioaerossóis, das medidas de controle de bactérias e fungos no ar e da viabilidade do uso deste reator de neblina ativada na redução de bioaerossóis, na bacia de chorume de um aterro sanitário.

\section{Opções tecnológicas para abatimento de bioaerossóis}

Vários são os sistemas desenvolvidos para abatimento de aerossóis. Cada um deles tem seus prós e contras, e nenhum reduz inteiramente os bioaerossóis de forma constante, sem resultar em outro tipo de poluição, com custo viável.

Em 2001, Kühner utilizou membranas semipermeáveis para reduzir a emissão de bactérias através de pilhas. Ao utilizar membranas em pilhas estáticas, as emissões bioaerossol ao longo de todo o processo da estação de compostagem puderam ser reduzidas em $83 \%$ em relação a pilha $\mathrm{C}$ sem membrana, independentemente das espécies de microorganismos. 
Schilling (2003) mostrou resultados de redução na concentração de Aspergillus fumigatus na entrada e saída de ar em biofiltros instalados em estações de tratamento de resíduos. Os dados medidos confirmam que os Aspergillus fumigatus foram retidos por um biofiltro quando operado adequadamente, embora com diferentes eficiências. As concentrações mínima e máxima de microrganismos termotolerantes na saída do ar foram até duas ordens de grandeza inferiores à concentração inicial.

O uso de membranas e de biofiltros apresentam duas desvantagens: a primeira é a queda da eficiência na redução dos microorganismos ao longo do tempo, onde as eficiências máximas são obtidas apenas durante um determinado período, para depois decaírem, resultando na necessidade da sua substituição periódica, a segunda desvantagem é a necessidade de disposição adequada das membranas e biofiltros usados de forma semelhante à disposição de resíduo hospitalar. A combinação de substituições regulares dos biofiltros e custo da disposição encarecem a sua adoção.

Jaeschke e colaboradores (1998), do Centro de Pesquisas Ambientais da Universidade de Frankfurt, entre outros pesquisadores, demonstraram que, na natureza, a neblina é o mecanismo mais eficiente para captação de poluentes atmosféricos. (JAESCHKE et al., 1998; RICCI et al., 1998) Baseado nesse conhecimento, Schumann (2000), sob a orientação do Prof. Jaeschke, utilizou uma neblina produzida artificialmente e ativada quimicamente para reduzir as emissões dos gases amônia, de compostos reduzidos de enxofre gasosos e gases orgânicos emitidos para a atmosfera de atividades industriais. (SCHUMANN, 2000) Essa técnica apresentava como vantagens sobre as outras o fato de ser de baixo custo, não gerar resíduos e apresentar desempenho constante sem flutuações. Essa técnica, embora aplicada a substâncias gasosas, tinha a possibilidade de ser utilizada na redução de partículas desde que a ativação química fosse modificada.

O Laboratório de Química Analítica Ambiental do Instituto de Química tinha uma parceria com o grupo do Prof. Jaeschke para medidas de compostos reduzidos de enxofre (CRE) de áreas naturais e industriais (NUNES et al., 2005), estendida a utilização do sistema para a redução de emissão de CRE e de amônia da bacia de acumulação de chorume do aterro sanitário de Salvador. Um sistema para testes de viabilidade - e modelo para outros a serem construídos no Brasil - 
foi concebido e construído na Alemanha, nas oficinas da Universidade de Frankfurt e trazido para a UFBA. Esse sistema consta basicamente de um nebulizador, de um tubo reator onde o ar a ser limpo reage com a neblina ativada quimicamente, e ao fim de um desnebulizador que recompõe o líquido da neblina, conduzindo-o para o esgotamento sanitário. Todo o estudo, otimização de tamanho de partículas e densidade da neblina, uniformidade ao longo do raio de eficiência de comprimento do reator, assim como a eficiência de desnebulização, foram procedidas previamente pelo grupo alemão na Universidade de Frankfurt.

Em 2009, Alves, na sua dissertação de mestrado, estudou a viabilidade da aplicação da técnica de neblina ativada com o mesmo sistema, para reduzir os microorganismos emanando da mesma bacia de acumulação de chorume. Como a técnica antes só havia sido utilizada na redução de substâncias gasosas de caráter ácido ou básico, e nesse caso, por tratar-se de redução de partículas, modificações no sistema de ativação química tornaram-se necessários. Tratando-se de abatimento de uma mistura de microorganismos de natureza desconhecida, portanto com grande probabilidade de tratar-se de uma mistura de natureza hidrofílica e lipofílica de partículas, optamos por utilizar surfactantes que são moléculas capazes de reagir com ambos os tipos de partículas por possuírem uma extremidade polar (solúvel em água) e outra apolar (solúvel em lipídios). Também nessa etapa, tivemos a colaboração dos parceiros alemães que forneceram alguns dos reagentes de ativação da neblina que não eram disponíveis comercialmente no Brasil. A seguir, descreveremos em mais detalhes esse novo sistema desenvolvido para reduzir as emissões de bactérias e fungos da bacia de chorume.

\section{Descrição do sistema de abatimento de bioaerossóis desenvolvido para o aterro sanitário de Salvador}

A bacia de acumulação de chorume do aterro sanitário de Salvador é coberta com uma lona plastificada, contendo uma saída, denominada respirador, por onde saem os gases e os microorganismos resultantes da decomposição da matéria orgânica. Na saída do respiradouro coloca-se um reator contendo neblina ativada quimicamente. Assim, o ar oriundo da bacia entra diretamente no reator, é purificado pela neblina ativada quimicamente, e é então lançado para a atmosfera. 
Neblina é a suspensão no ar de gotículas microscópicas de água ou de partículas higroscópicas úmidas, com diâmetro de partícula igual ou menor que 50 micrômetros, ou seja, 0,05 mm. Na natureza, a neblina se forma por condensação da umidade do ar (vapor d'água), por contato com massas de ar frias. A neblina artificial pode ser produzida por diversas formas, sendo a mais comum e barata por aspersão, ou seja, por um dispositivo pequeno instalado na extremidade de um fluxo de líquido sob pressão, que fraciona o líquido em gotículas por impactação em uma superfície. Aspersores são geralmente utilizados em irrigação e em resfriamento de unidades de produção confinada de aves, entre outros. Nesse caso as partículas de água produzidas são maiores do que 50 micrômetros. No entanto, para a produção de partículas de neblina, é preciso o uso de aspersores especiais, que produzam partículas menores que 50 micrômetros. Para a purificação do ar, quanto menores as partículas produzidas, mas eficiente será a captação de contaminantes.

No contexto de formação de neblina, denomina-se ativação química a adição de pequenas quantidades de uma ou mais substâncias químicas, que irão interagir com substâncias gasosas ou com as partículas presentes no ar.

O mecanismo de interação da neblina ativada com os bioaerossóis pode ser descrito da seguinte maneira e ilustrado na Figura 1. O fluxo de ar a ser limpo é tratado com gotículas de neblina ativadas quimicamente. A neblina e o ar fluindo para o reator e contendo os bioaerossóis são transportados ao longo do reator pelo fluxo do ar. Depois de um curto tempo de contato os bioaerossóis são adsorvidos pela superfície das gotículas de neblina ativadas quimicamente, com uma mistura de surfactantes e de outros compostos em nível de traço, os quais dependem da composição original do ar. A determinação da eficiência da interação - e, portanto, da purificação - é feita quantificando-se os bioaerossóis no ar antes e depois da passagem do ar pela neblina. 
Figura 1 - Esquema do funcionamento da neblina ativada na captação de bioaerossóis.

Reator de absorção de bioaerossol

- Neblina

- Aerossol / Bactéria

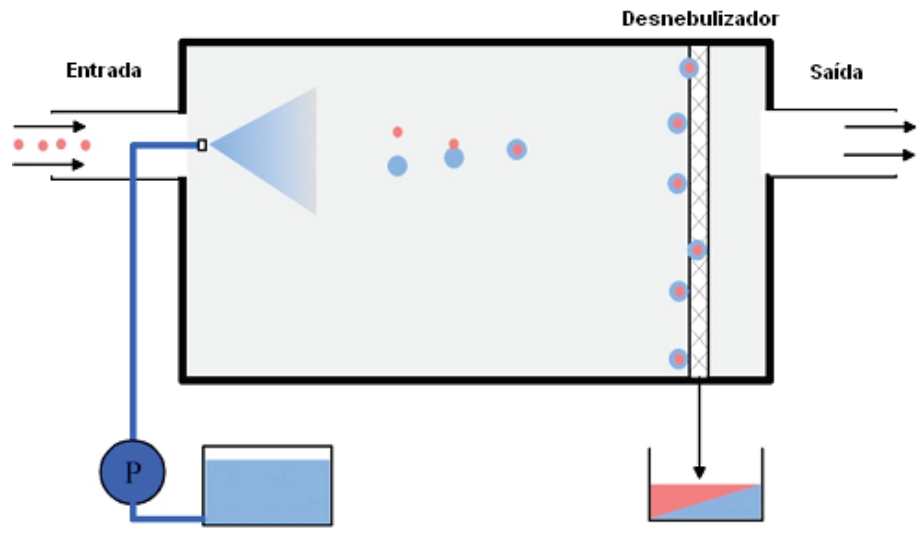

Fonte: JAESCHKE, não publicado, com modificações. In: TAVARES,

T. M. et al., Apresentação feita à Battre. Salvador. BA, dez. 2006.

O sistema de abatimento de bioaerossóis utilizado foi consistido por um reator de PVC de $5 \mathrm{~m}$ de comprimento, um gerador de neblina com dois aspersores e um aspirador do gás a ser limpo. Esse reator foi instalado na saída da bacia de chorume do aterro sanitário de Salvador.

O gerador de neblina foi composto por uma bomba que leva a solução de limpeza até o aspersor, responsável pela formação da neblina com partículas de 0,2 - $20 \mu \mathrm{m}$ e situado na entrada do reator. Um segundo aspersor, idêntico ao primeiro, foi utilizado para aumentar a eficiência do sistema, formando uma neblina mais densa. Na extremidade da saída do reator foi colocado um desnebulizador em forma de tela de aço inox, que permite somente a passagem do ar limpo, recompondo a solução dispersa como neblina e contendo os bioaerossóis, a qual é descartada ou direcionada para o sistema de esgotamento sanitário. As concentrações de bioaerossóis são pelo menos uma ou duas ordens de grandeza menores do que aquelas presentes em águas descartadas e circulando por esgotamento sanitário. Um esquema do reator sistema pode ser visto na Figura 2. 
Figura 2 - Esquema do sistema de neblina utilizado para abatimento de bioaerossol na bacia de acumulação do chorume do Aterro Sanitário Metropolitano Centro de Salvador.

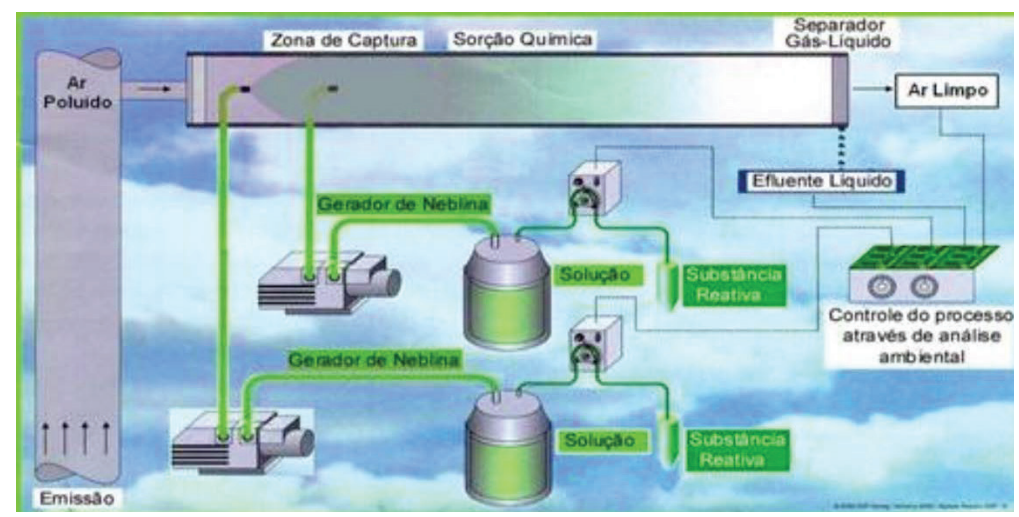

Fonte: JAESCHKE, não publicado, com modificações. In: TAVARES, et al. Apresentação feita à Battre. Salvador. BA, dez. 2006.

\section{Medidas de bioaerossóis: controle de bactérias e fungos no ar}

$\mathrm{O}$ ar foi amostrado com o impactador de cascata Andersen, operado apenas com um estágio, com fluxo constante de ar aspirado de $28,3 \mathrm{~L}$ min $^{-1}$ coletando as partículas acima de diâmetro aerodinâmico de corte 0,4 $\mu \mathrm{m}$. Um sistema de pressão para vedação do sistema utilizado dessa forma foi desenhado e construído especialmente em oficina mecânica local. A Figura 3 mostra o impactador Andersen montado com apenas um estágio. O fluxo constante foi obtido com uma bomba de vácuo de regime contínuo, provida com uma válvula de controle ajustável. A vazão, antes e depois de cada amostragem, foi medida com um rotâmetro marca Rota de fabricação alemã, previamente calibrado. 
Figura 3 - Impactador Andersen de um estágio utilizado para amostrar bioaerossóis no ar entrando e saindo do reator de neblina ativada.

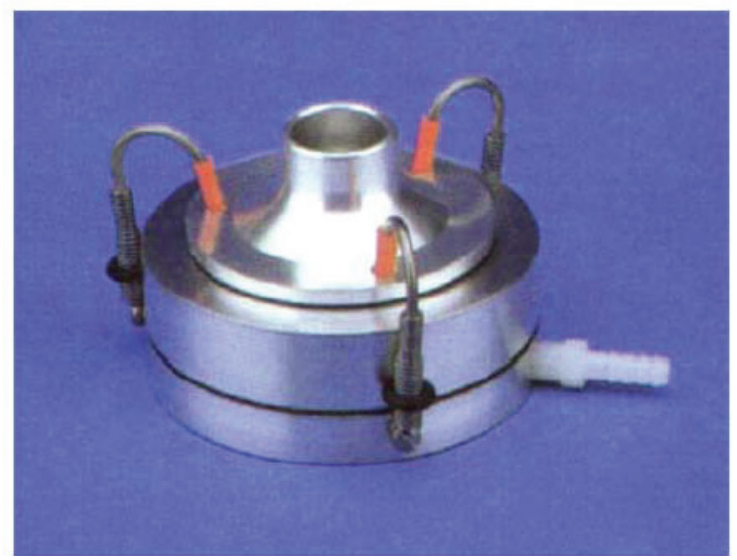

Fonte: (ALVES, 2009)

O meio de coleta foi uma membrana de ésteres mistos de celulose hidrofílicos, poro 0,45 $\mu \mathrm{m}$, diâmetro $80 \mathrm{~mm}$, GN6 - Metricel da Pall, que minimiza artefatos, quais sejam, a inibição ou o estímulo indevido de desenvolvimento de culturas que se seguirão. Estando a umidade relativa do ar alta, tornou-se desnecessário o uso de umedecimento prévio da membrana para evitar repique das partículas ou dessecação e morte das bactérias. O tempo de coleta de cada amostra foi de $10 \mathrm{mi}$ nutos, num total de volume amostrado de $283 \mathrm{~L}$.

Após a amostragem, as membranas foram colocadas em contato com as placas Petrifilm contendo as duas culturas respectivamente, de bactérias e fungos, previamente umedecidas com $1 \mathrm{~mL}$ de água esterilizada por micro filtração, e mantidas a temperatura ambiente no campo. Após a amostragem, as membranas foram colocadas em contato com os meios de cultura adequados.

O meio de cultura para bactérias foi ágar padrão com incubação posterior à chegada ao laboratório de microbiologia, com incubação a $35^{\circ} \mathrm{C} \pm 1^{\circ} \mathrm{C}$ por $48 \mathrm{~h} \pm 3 \mathrm{~h}$. O meio de cultura para fungos foi ágar Sabouraud, com incubação posterior à chegada ao laboratório durante 5 dias entre $20-25^{\circ} \mathrm{C}$. As contagens das colônias desenvolvidas foram feitas visualmente e quando necessário, com auxílio de um contador composto de uma lupa e uma lâmpada. 
A concentração total de microrganismos cultiváveis foi calculada dividindo-se o número total de colônias observadas em todas as placas pelo volume do ar amostrado. Concentrações de bioaerossóis cultiváveis são relatadas normalmente como unidades de formação de colônias (UFC), que é o número de colônias que se replica de células de bactérias individuais ou em grupos, endoesporos ou esporos fúngicos, por unidade de volume do ar $\left(\mathrm{m}^{3}\right)$. O volume de ar é dado pela vazão de amostragem multiplicada pelo tempo decorrido da amostragem:

$V=\frac{Q \cdot t}{1000} V=\frac{Q \cdot t}{1000}$, onde $\mathrm{V}$ é volume $\left(\mathrm{m}^{3}\right)$, Q é vazão $\left(\mathrm{L} \mathrm{min}^{-1}\right)$ e $\mathrm{t}$ é
tempo (min).

Para verificar se existe diferença entre as concentrações de bioaerossóis determinadas antes e após a intervenção, foi utilizado o teste t de Student, que é teste de hipótese para comparação de médias de pequenas amostras dependentes. A eficiência do sistema foi calculada com base na percentagem referente à concentração de microrganismos obtidos após a intervenção, relacionados com as concentrações determinadas antes da intervenção com o sistema proposto.

$$
\eta=\frac{C_{\text {inicial }}-C_{\text {final }}}{C_{\text {inicial }}} \cdot 100
$$

\section{A viabilidade do uso do reator de neblina ativada na redução de bioaerossóis na bacia de chorume do aterro sanitário}

O sistema de neblina ativada foi testado em duas condições: neblina sem e com a mistura de tensoativos $1 \%$, tanto para bactérias quanto para fungos. Os resultados em unidades de formação de colônias por metro cúbico de ar (UFC $\mathrm{m}^{-3}$ ) obtidos do ar sem nenhum tratamento, denominado de inicial, e do ar saindo do sistema de tratamento com a neblina ativada, denominado de final, foram reportados para cada microrganismo.

Comparando-se os valores de UFC $\mathrm{m}^{-3}$ saindo do respiradouro da bacia de chorume (coluna denominada Inicial) e os valores equivalentes saindo do sistema de neblina (coluna denominada final), nota-se que a ação da neblina sem ativação química consegue reduzir em média 
$71,9 \%$ das bactérias presentes e com a ativação resultante da presença da mistura tensoativa a $1 \%$, a redução alcança $93,5 \%$.

Figura 4 - Concentração de bactérias (UFC $\mathrm{m}^{-3}$ ) no ar emanado do respiradouro da bacia de acumulação do chorume do Aterro Sanitário Metropolitano Centro de Salvador, antes e depois da passagem pelo reator de neblina ativada.

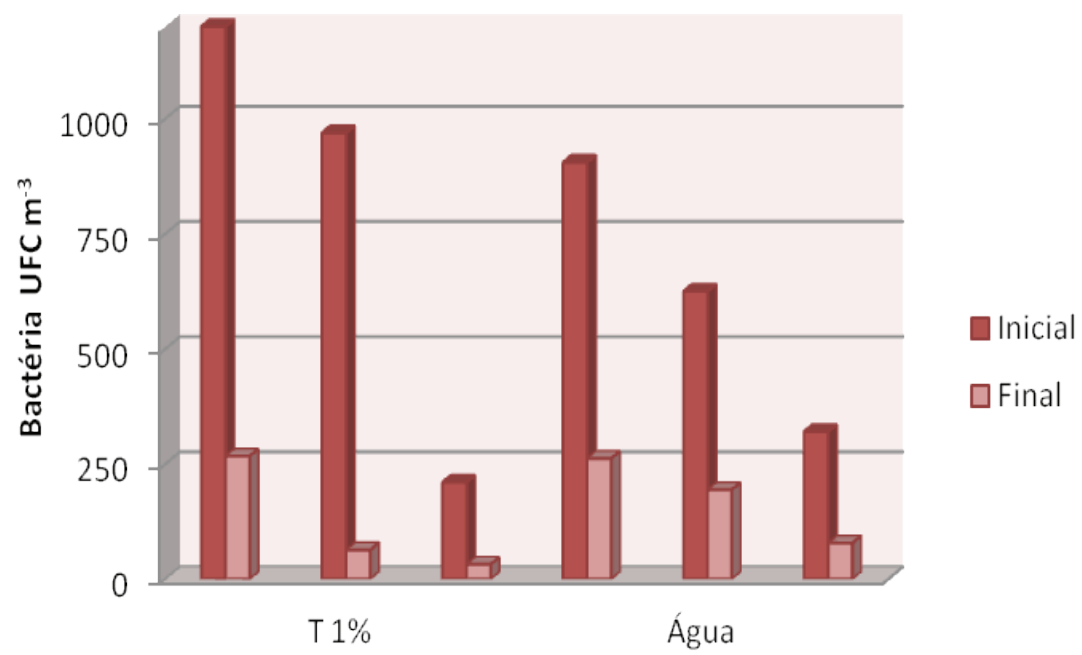

Tipo de neblina

Fonte: (ALVES, 2009)

O teste $\mathrm{t}$ foi aplicado ao conjunto de dados do sistema antes e depois dos tratamentos com neblina (água e mistura química tensoativa). $\mathrm{O}$ valor calculado (Stat $\mathrm{t}=4,351755956$ ) é maior que o valor crítico bi-caudal (t crítico bi-caudal $=2,570581835$ ), e a hipótese de igualdade $\left(\mathrm{H}_{0}\right)$ é rejeitada. Podemos chegar à mesma conclusão comparando o valor do $\mathrm{p}$-value $(\mathrm{P}(\mathrm{T}<=\mathrm{t})$ bi-caudal $)=0,023039$ com o nível de significância adotado $\alpha=0,05$. Como $\alpha>$ valor-p, rejeita-se a hipótese $\mathrm{H}_{0}$. Desta forma, é possível dizer que a concentração de bactérias no ar antes da utilização do sistema é significativamente diferente da concentração após a aplicação da neblina.

Os dados obtidos para fungos podem ser vistos na Figura 5. Cada valor constante nesse gráfico representa a média aritmética de medidas em duplicata. Comparando-se os valores de UFC $\mathrm{m}^{-3}$ de fungos saindo do respiradouro da bacia de chorume (coluna denominada inicial) e os valores equivalentes saindo do sistema de neblina (coluna denomina- 
da final), vemos que a ação da neblina sem ativação química consegue reduzir em média $72,1 \%$ dos fungos presentes, de forma semelhante ao ocorrido com a redução de bactérias. Com a ativação tensoativa a redução alcança 93,4\%, também semelhante à redução de bactérias.
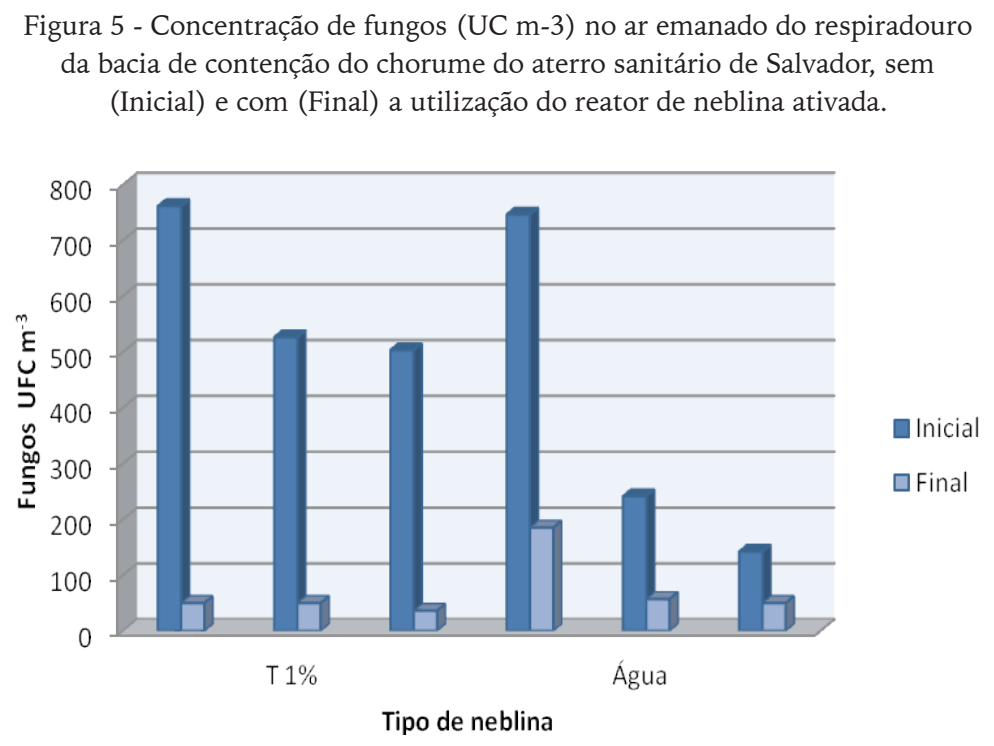

Fonte: (ALVES, 2009)

O teste $t$ foi aplicado ao conjunto de dados das medidas de fungos antes e depois dos tratamentos com neblina (sem ativação e com ativação tensoativa). Como o valor calculado (Stat $t=4,351755956)$ é maior que o valor crítico bi-caudal ( $\mathrm{t}$ crítico bi-caudal $=2,570581835$ ), rejeita-se a hipótese $\mathrm{H}_{0}$ de que a concentração de fungos no ar não difere significativamente, antes e depois da utilização do sistema. $(\mathrm{P}(\mathrm{T}<=\mathrm{t})$ bi-caudal $)=0,007347042$ com o nível de significância adotado de $\alpha=0,05$ Como $\alpha>$ p, rejeita-se a hipótese $\mathrm{H}_{0}$. Desta forma é possível dizer que a concentração de fungos no ar, antes da utilização do sistema, é significativamente diferente da concentração após a aplicação da neblina.

Os dados resultantes da aplicação do sistema de neblina ativada sugerem que as especificações do reator construído e a ativação química utilizada, reduzem em até $93 \%$ as bactérias e fungos do ar nas emissões de bioaerossóis de uma lagoa de chorume de um aterro sanitário. 
Nessas mesmas condições esse sistema reduziu em até $98 \%$ a emissão de gases com mau odor, dessa mesma bacia de contenção de chorume. (CRUZ et al., 2005) A eficiência na redução de gases e bioaerossóis dependem, além da composição e da concentração da mistura química tensoativa, de vários outros fatores da engenharia do equipamento, tais como a faixa de tamanho de gotículas da neblina produzida pelo aspersor e especificação de construção do reator. Portanto, a utilização do reator proposto é viável para a redução de bactérias e fungos e otimizações são possíveis para uma redução ainda maior.

\section{Considerações finais}

Embora seja consenso internacional que atividades de disposição e aterro de resíduos orgânicos emitam bioaerossóis para o ar, existem poucos estudos identificando e quantificando os microorganismos emitidos de aterros sanitários em geral, e de bacias de acúmulo de chorume em particular. As emissões atmosféricas de bactérias e fungos do aterro sanitário metropolitano de Salvador, foram comprovadas e quantificadas no estudo relatado neste capítulo.

Estudos internacionais demonstram que os bioaerossóis emitidos em plantas de compostagem - as quais vêm sendo mais estudadas a partir de 2000 - são transportados a distâncias de 1000 m ou mais. Estudos adicionais, principalmente na Alemanha, demonstraram que essas emissões afetam a saúde humana e bem estar de residentes próximos. Essa comprovação aponta para a necessidade de desenvolver-se sistemas que reduzam ou abatam os microorganismos lançados ao ar.

Algumas técnicas vêm sendo aplicadas para essa finalidade em plantas de compostagem. No entanto, as técnicas utilizadas apresentam grandes desvantagens, tais como: desempenho variável ao longo do tempo, necessidade de substituição periódica de membranas ou filtros, e geração de resíduos sólidos demandando disposição especial semelhante às de resíduos hospitalares. Outras envolvem consumo muito alto de energia, tornando-se dispendiosas.

O sistema desenvolvido na UFBA, resultado da parceria do Mestrado de Saúde, Ambiente e Trabalho e o Laboratório de Química Analítica Ambiental do Instituto de Química, baseia-se no princípio da neblina ativada quimicamente, conseguindo reduzir as emissões de 
microorganismos emitidos pela bacia de contenção de chorume do aterro sanitário metropolitano de Salvador em cerca de 93\%. O sistema de neblina ativada atua dentro de um reator cilíndrico colocado na saída do ar da bacia. O sistema é de custo baixo, desempenho estável ao longo do tempo, não gerando resíduos ou efluentes contaminados, além de não necessitar de substituição periódica. Como desvantagens de sua aplicabilidade no Brasil, estão a falta de disponibilidade comercial no mercado nacional de aspersores capazes de produzir partículas de diâmetro entre 10 e $20 \mathrm{um}$ - tamanho de partícula da neblina utilizada no sistema construído pelos parceiros alemãs - e das misturas tensoativas de produção estrangeira.

O sistema desenvolvido e aqui descrito comprova a viabilidade do uso da técnica da neblina ativada para purificação do ar contaminado por microorganismos emitidos por uma bacia de acúmulo de chorume. A eficiência $93 \%$ alcançada, embora alta, pode ser aumentada, necessitando-se para isso outros testes, modificando-se vários parâmetros, tais como concentração da solução tensoativa, composição alternativa do tenso ativo, dimensões do reator, fluxo do ar a ser purificado, entre outros.

Além dessa aplicação, o sistema apresenta o potencial de ser aplicado a outras situações, tais como purificação de plantas de compostagem, de tratamento de efluentes contendo matéria orgânica, de unidades de separação de lixo - inclusive utilizado pelos catadores -, de tratamento biológico de efluentes industriais em geral e de plantas de papel celulose em particular, entre outros. Devido ao potencial da técnica de neblina ativada, de abater não apenas partículas, mas também gases, e devido a sua flexibilidade para a construção de outros arranjos, sua gama de possibilidades de aplicação na purificação de ar são enormes.

\section{Referências}

ALBRECHT, A. et al. Recommendations for study design and sampling strategies for airborne microorganisms, MVOC and odours in the surrounding of composting facilities. International Journal of Hygiene and Environmental Health, v. 211, n. 1-2, p. 121-131, 2008.

ALVES, E. M. Uso de Neblina ativada para redução das emissões de bioaróssois em um aterro sanitário, 2009. 66f. 
Dissertação (Mestrado em saúde, ambiente e trabalho) Faculdade de Medicina, Universidade Federal da Bahia, 2009.

BUNGER, J. et al. A 5-year follow-up study on respiratory disorders and lung function in workers exposed to organic dust from composting plants. International Archives of Occupational and Environmental Health. v. 80, n. 4, p. 306-312, 2006.

CROOK, B.; BARDOS, R. P.; LACEY, J. Domestic waste composting plants as sources of airborne micro-organisms. Congress on Aerosols, Their Generation, Behaviour and Applications, 22-24 March 1988, Bournemouth, UK. Proceedings Bournemouth: the Aerosol Society Second Conference, 1988.

CRUZ, L. P. S. et al. Otimização de sistema químico de neblina temperada para abatimento de emissões atmosféricas de $\mathrm{H}_{2} \mathrm{~S}$. Reunião Anual da Sociedade Brasileira de Química, 28ª , 2005, Poços de Caldas - MG. Livro de Resumos, 2005.

FISCHER, G. et al. Exposure to airborne fungi, MVOC and mycotoxins in biowaste-handling facilities. International Journal of Hygiene and Environmental Health, v. 203, n. 2, p. 97-104, 2000.

. Analysis of airborne microorganisms, MVOC and odour in the surrounding of composting facilities and implications for future investigations. International Journal of Hygiene and Environmental Health, v. 21, n. 1-2, p. 132-142, 2008.

FRANK, W. G. Size and Characteristics of Airborne Solids. New York: American Air Filter Company, 1937.

HERR, C. E. W. et al. Bioaerosols in outdoor air - Statement of environmental medical assessment criteria on the basis of an epidemiological cross sectional study. Gefahrstoffe Reinhaltung Der Luft. v. 64, n. 4, p. 143-152, 2004 a.

. Health effects associated with exposure to residential organic dust. American Journal of Industrial Medicine. n. 46, p. 381-385, 2004b.

JAESCHKE, W. et al. Mass fluxes and chemical pathways during a fog event. Contr. Atmos. Phys. n. 71, p. 145-157, 1998.

KOWALSKI, W. J.; BAHNFLETH ,W. Airborne Respiratory Diseases and Mechanical Systems for Control of Microbes. HPAC Heating/Piping/Air Conditioning, p. 34-48, 1998.

KÜHNER, M. Kompostierung unter semipermeablen Membranen. Stuttgarter Berichte zur Abfallwirtschaft, Bd. p. 78, 2001. 
KUMMER, V. et al. Untersuchungen zum Abscheide-verhalten von Abluftreinigungsanlagen im Hinblick auf Bioaerosole.

Gefahrstoffe. Reinhaltung der Luft, n. 63, p. 368-372, 2003.

MILLNER, P. Bioaerosols and composting. Bio Cycl, v. 36, n. 1, p. 48-54, 1995.

MOHR, A. J. Microorganisms fate and transport. In: HURST, C. J. et al. Manual of Environmental Microbiology, 2 ed. Washington DC: ASM Press. 2002. p. 827-838,

MULLER, T. et al. Acute Blood Neutrophilia Induced by ShortTerm Compost Dust Exposure in Previously Unexposed Healthy Individuals. International Archives of Occupational and Environmental Health. n. 79, p. 477-482, 2006.

NUNES, L. S. S. et al. Measurements of Atmospheric Concentrations of Reduced Sulphur Compounds in the All Saints Bay Area in Bahia, Brazil. Journal of Atmospheric Chemistry, n. 50, p. 79-100, 2005.

RAHKONEN, P. Airborne Contaminants at Waste Treatment Plants, Waste Manag. Res., v. 92, n. 10, p. 411-421. 1992.

RECER, G. M. et al. Ambient air levels of Aspergillus fumigatus and thermophilic actinomycetes in a residential neighbourhood near a yard waste composting facility. Aerobiologia, n. 17, p. 99-108, 2001.

RICCI, L. et al. Gas-Liquid Equilibria in Polluted Fog.

Contr. Atmos. Phys. n. 71, p. 159-170, 1998.

SCHILLING, B. Emissionsminderung für Bioaerosole durch Biofilter. In: Mikroorganismen in der Umgebung von Abfallbehandlungsanlagen Hessisches Landesamt für Umwelt und Geologie. 2003.

SCHUMANN, M. Nutzungsmöglichkeiten der Chemisorption mit Nebeltropfen zur Minderung der Emission Von Ammoniak, Schwefelwasserstoff und organischen Gasen aus Industriebetrieben. Enthalten im Sonderforschungsbericht 233, Dynamik und Chemie der Hydrometeore, Zentrum für Umweltforschung, 2000. 